\title{
Association of Diabetes Mellitus and Nutritional Status in Children 7 to 11 Years with High Birth weight
}

\author{
Nuris Rodriguez Vargas ${ }^{1 *}$, Jose Emilio Fernandez -Britto², Tania P Martinez Pérez ${ }^{1}$, Rolando Marti- \\ nez García ${ }^{3}$, Cecilia Castañeda García ${ }^{1}$, Rosa Maria Garcia Niebla ${ }^{1}$, Lic. Teresita Rojas González ${ }^{1}$, Lic. \\ Mailin Garriga Reyes ${ }^{4}$
}

\begin{abstract}
${ }^{1}$ Department of Medical Sciences, "Manuel Fajard” Medical University of Havana, Havana, Cuba
${ }^{2}$ Department of Science, Research Center of Havana Reference Atherosclerosis ( CIRAH ), Medical University of Havana, Havana, Cuba

${ }^{3}$ Department of Computer Science, Faculty of Medical Sciences Carlos J Finlay Medical University of Havana, Havana, Cuba ${ }^{4}$ Medical University of Physical Culture, National Institute of Cardiology and Cardiovascular Surgery, Havana Cuba
\end{abstract}

"Corresponding author: Nuris Rodriguez Vargas, Department of Medical Sciences, "Manuel Fajardo" Medical University of Havana, Havana, Cuba, E-mail: nuris@infomed.sld.cu

\begin{abstract}
Introduction: Diabetes Mellitus type 2 (DM2) is a chronic disease characterized by absolute or relative failure of a hormone produced by the pancreas, called insulin and is characterized by an alteration in the metabolism of proteins, fats and carbohydrates $^{[1-3]}$.

Objective: Identify whether the high birth weight in children aged 7 to 11 years is a predictor for the association of overweight and obesity with diabetes mellitus.

Method: A descriptive study was conducted with a design case - control with children born between January 1992 and December 1995.

Results: Encontramos in the study group that overweight $2.85 \%$ is pre diabetic and 1 , $44 \%$ diabetic, in obese $1.42 \%$ is pre-diabetic and diabetic $3.56 \%$, where there Fisher's $\mathrm{P}=0.0002$ association between nutritional status (overweight, obesity) pre diabetes and diabetes; in the control group, in overweight we found that $3.00 \%$ diabetic and diabetic pre $0.00 \%$ in obese diabetic pre $1.00 \%$ and $2.00 \%$ with a diabetic Fisher's $\mathrm{P}=0$, 0343 , existing association between nutritional status and pre-diabetes and diabetes in this group association between nutritional status and diabetes was also found, so there is no difference in the two groups, but we must note that in the study group his association was stronger. In our study is not high birth weight per, association for diabetes. Conclusion: The high birth weight (macrosomia) does not constitute per se a predictor for the association of malnutrition by excess and diabetes, association for excess malnutrition and diabetes in both groups.
\end{abstract}

Received date: April 24, 2016

Accepted date: June 09, 2016

Published date: June 13, 2016

Citation: Nuris, R.V., et al. Association of Diabetes Mellitus and Nutritional Status in Children 7 to 11 Years with High Birth weight. (2016) J Diabetes Obes 3(1): 22- 26.

DOI: $10.15436 / 2376-0494.16 .882$

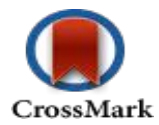

\section{Introduction}

It is not known in the literature research related to factors of arteriosclerotic risk (accelerators) and high birth weight and less association of malnutrition by excess and diabetes in high birth weight for more than 15 years ago, we investigate factors of arteriosclerotic irrigation (accelerators atherosclerosis) in children with high birth weight, investigation case-control (with child of normal birth weight), age 7 to 11 years, because it referred not notes that are macrosomia, except for recent works, although not established association of these risk factors (accelerators) with high birth weight and no basis at this age ${ }^{[4-7]}$ for what most studied is low birth weight, that given our knowledge and experience, are of the opinion that low birth weight is not a predictor per se for arteriosclerotic risk factors also in our view are not risk factors if there accelerators arteriosclerosis, because as it is known, it starts from the fertilization of the egg and sperm when genetic discharge occurs because pathological studies show the fat streaks have been observed in young children. 
Diabetes Mellitus type 2 (DM-2) is a chronic disease characterized by absolute or relative failure of a hormone produced by the pancreas, called insulin and is characterized by an alteration in the metabolism of proteins, fats and carbohydrates ${ }^{[1-3]}$. The speed with which frequency has increased, mainly due to the changes occurring in lifestyle in recent years, now have become a public health problem ${ }^{[8,9]}$ which compromises the quality of life of a large number of people and the destination of a significant amount of resources ${ }^{[10,11]}$.

Once considered a disease of adults, but with the increased rate of childhood overweight and obesity and especially in the school on our experience and considered the same as the epidemic of the century, this leads to excess fat causes resistance insulin, bone that action of insulin which is responsible for facilitating the entry of blood glucose into cells, it does not act in an appropriate manner.

There were an estimated 135 million diabetics in 1995 in the world, a figure that is thought to reach 300 million in $2025^{[12]}$. In Mexico, in 1997 there were 4 million people, between 20 and 69 years with this disease.

It is vital to diagnose the diabetic patient as soon as possible, and care for the diabetic and diagnosed understand the seriousness of the process, subsequent complications, and assume a commitment to comprehensive health care, including drastic changes in lifestyles that go far beyond simple compliance with drug routines ${ }^{[13]}$.

Its appearance, and the development and severity of its complications, is closely related to timely diagnosis and adequate control of glucose levels in diabetic patients, highly linked to complex behavioural changes ${ }^{[14-16]}$ event. it is considered that diabetes mellitus is on the verge of a pandemic and suggests that there are diagnosed every two diabetics undiagnosed or two walking without knowing of his illness and that he is losing precious time and its complications are more severe and early

\section{Objective}

Identify whether the high birth weight in children aged 7 to 11 years is a predictor for the association of overweight and obesity with diabetes mellitus.

\section{Material and Method}

A descriptive study was conducted with a design case - control with children born between January 1992 and December 1995 in order to identify early risk factors (atherosclerotic accelerators) in children 7 to 11 years, they have a history of macrosomia or high birth weight.

\section{Universe and Sample}

The universes consists of all children born at the obstetrician Hospital Ramón González Coro belonging to the municipality Plaza de la Revolution, with a history of macrosomia or high birth weight and are a total of 140 children and a sample of 100 children with normal weight, a non-randomized sample of intent was selected, based on the following criteria:

- Residents in the municipality Plaza de la Revolution at birth.

- Current residence in the municipality.

- Consent family (mom) to participate in the study.

To conduct the research two groups were created. One we call macrosomic group and that integrated children (140) with high birth weight (4,000 grams or more) and another we call the integrated control children (100) with normal birth weight group.

\section{Definition, Categorization and Operationalization of Variables \\ Variables relating to child}

Child's age: continuous numeric variable that refers to the time elapsed years between birth and the time of data collection. It was obtained as a result of questioning the family and for the purpose of this study was discretized and categorized into two cliques with amplitude of 3 years as follows:

- 7 to 9 years

- 10 to 11 years

Body Mass Index (BMI): continuous variable number. Indicator used to assess the nutritional status of the child. Also known as Quetelet index, it was obtained by the weight $(\mathrm{kg}) /$ height (in $\mathrm{cm}$ ) relationship. To get it was necessary to measure two intermediate variables were:

1. Current weight: Continuous numeric variable. It was obtained in kilograms to the nearest tenth, with little clothing as possible.

2. Current Size: continuous numeric variable whose result is expressed in centimeters. Only integer values were taken. The patient at anthropometric position, barefoot with body straight, his head was placed in the plane of Frankfort, in weight-stadiometer Chinese-made equipment, obtaining the results in centimeter.

After obtained the data and evaluate the nutritional status was classified according to the Cuban tables BMI percentiles of children and adolescents 1982, as follows:

- Malnourished: below the $3^{\text {rd }}$ percentile

- Thin: between $3^{\text {rd }}$ and $10^{\text {th }}$ percentile to the

- Normal weight: above the $10^{\text {th }}$ percentile and up to 90 
- Overweight: above 90 and up to 97 percentile

- Obese: above the $97^{\text {th }}$ percentile

Birth weight: continues numeric variable refers to the weight of the child in kilograms at birth.

Glycemia: quantitative continuous variable that was taken dichotomously to determine whether or no change in blood glucose levels according to laboratory results. Thus it was categorized into:

- Normal: $(3,2 \mathrm{mmol} / 1-5,6 \mathrm{mmol} / \mathrm{l})$

- Pre diabetic $(5.6-6.9 \mathrm{mml} / \mathrm{l})$

- Altered (diabetic): (= or $>7 \mathrm{mmol} / \mathrm{l})$

\section{Techniques and Procedures Information Gathering}

Data collections for primary and secondary sources were used. The interview and observation were used as fundamental techniques in gathering information from primary sources. The book obstetrician delivery of Hospital Ramón González Coro hospital's medical history, baby birth card and Card Pregnant constituted secondary sources of information used.

Each child was previously visited to tell their turn for consultation. There a medical history with personal data, personal and family medical history, dietary issues related to the birth data and a thorough physical examination including anthropometric study, taking blood pressure, blood glucose humoral study as among others was made.

\section{Results}

School between 7 and 11 years who were enrolled in primary education were studied. The study population was represented by 140 and 100 control group, of which the distribution is presented according to age Table I, as follows, between 7 and 9 years, $56.43 \%$ in the study group, $54,00 \%$ in the control group and the aged of 10 to 11 years $43.57 \%$ in the study group and $46.00 \%$ in the control group, no statistically significant differences were found between the two groups, as the average age is 9.06 and 9.22 for sample control group with a $\mathrm{t}=0.7047$ and $\mathrm{p}=0.4818$.

Table I: Distribution of the sample by age group and control group study

\begin{tabular}{|c|c|c|c|c|c|c|}
\hline \multirow{2}{*}{ EDAD } & \multicolumn{2}{|c|}{ STUDY GROUP } & \multicolumn{2}{|c|}{ CONTROL GROUP } & \multicolumn{2}{|c|}{ TOTAL } \\
\hline & $\mathbf{n}$ & $\%$ & $\mathbf{n}$ & $\%$ & n & $\%$ \\
\hline 7 A 9 & 79 & 56.43 & 54 & 54.00 & 133 & 55.42 \\
\hline $10 \mathrm{~A} 11$ & 61 & 43.57 & 46 & 46.00 & 107 & 44.58 \\
\hline Total & 140 & 100.00 & 100 & 100.00 & 240 & 100.00 \\
\hline Fisher's & \multicolumn{6}{|c|}{$\mathrm{p}=07925$ (not significant). } \\
\hline Average & \multicolumn{2}{|c|}{9,06} & \multicolumn{2}{|c|}{9.22} & \multicolumn{2}{|c|}{$\mathrm{t}=0.7047$} \\
\hline Standard deviation & \multicolumn{2}{|c|}{1,6954} & \multicolumn{2}{|c|}{1.7614} & \multicolumn{2}{|c|}{$\mathrm{p}=0.4818$} \\
\hline
\end{tabular}

Source: $\mathrm{AC}$ in consultation

Table II: Nutritional assessment of children according to classification Diabetes in the study group (macrosomic)

\begin{tabular}{|c|c|c|c|c|c|c|c|c|}
\hline \multirow{3}{*}{$\begin{array}{l}\text { NUTRITIONAL } \\
\text { ASSESSMENT }\end{array}$} & \multicolumn{6}{|c|}{ Classification of Diabetes } & \multirow{2}{*}{\multicolumn{2}{|c|}{ TOTAL }} \\
\hline & \multicolumn{2}{|c|}{ NORMAL } & \multicolumn{2}{|c|}{ PRE - DIABETIC } & \multicolumn{2}{|c|}{ DIABETIC } & & \\
\hline & $\mathbf{n}$ & $\%$ & $\mathbf{n}$ & $\%$ & $\mathbf{n}$ & $\%$ & $\mathbf{n}$ & $\%$ \\
\hline malnourished & 1 & 0,71 & 0 & 0,00 & 0 & 0,00 & 1 & 0.71 \\
\hline Delgado & 3 & 2,14 & 0 & 0,00 & 0 & 0,00 & 3 & 2.14 \\
\hline Normopeso & 84 & 60,00 & 0 & 0,00 & 0 & 0,00 & 84 & 60,00 \\
\hline Overweight & 21 & 15,00 & 4 & 2,85 & 2 & 1,44 & 27 & 19,29 \\
\hline Obese & 18 & 12,85 & 2 & 1,42 & 5 & 3,56 & 25 & 17,86 \\
\hline Total & 127 & 90,71 & 6 & 4,28 & 7 & 5,00 & 140 & 100.00 \\
\hline
\end{tabular}

Source: HC Consultation

In Table II, we found in the study group that overweight $2.85 \%$ is pre diabetic and diabetic $1.44 \%$ in the obese is pre $1.42 \%$ $3.56 \%$ diabetic and diabetic, where there Fisher's $\mathrm{P}=0.0002$ association between nutritional status (overweight, obesity) pre diabetes and diabetes; in the control group (Table III) found that overweight pre diabetic $3.00 \%$ and $0.00 \%$ in diabetic obese diabetic pre $1.00 \%$ and $2.00 \%$ diabetic with a Fisher's $\mathrm{P}=0.0343$, existing association between nutritional status and pre-diabetes and diabetes in this group association between nutritional status and diabetes was also found, so there is no difference in the two groups, but we must note that in the study group association was stronger. Normal weight children none were diabetic or pre-diabetic In our study is not high birth weight per se, an association for diabetes. 
Diabetes Mellitus and Nutritional Status in Children

Table III: nutritional assessment of children according to classification Diabetes in the control group.

\begin{tabular}{|c|c|c|c|c|c|c|c|c|}
\hline \multirow{3}{*}{$\begin{array}{l}\text { NUTRITIONAL ASSESSMENT } \\
\text { OF CHILDREN }\end{array}$} & \multicolumn{6}{|c|}{ Classification of Diabetes } & \multirow{2}{*}{\multicolumn{2}{|c|}{ TOTAL }} \\
\hline & \multicolumn{2}{|c|}{ NORMAL } & \multicolumn{2}{|c|}{ PRE - DIABETIC } & \multicolumn{2}{|c|}{ DIABETIC } & & \\
\hline & $\mathbf{n}$ & $\%$ & $\mathbf{n}$ & $\%$ & $\mathbf{n}$ & $\%$ & $\mathbf{n}$ & $\%$ \\
\hline malnourished & 4 & 4,00 & 0 & 0,00 & 0 & 0,00 & 4 & 4,00 \\
\hline Delgado & 4 & 4,00 & 0 & 0,00 & 0 & 0,00 & 4 & 4,00 \\
\hline Normopeso & 51 & 51,00 & 0 & 0,00 & 0 & 0,00 & 51 & 51,00 \\
\hline Overweight & 16 & 16,00 & 3 & 3,00 & 0 & 0,00 & 19 & 19,00 \\
\hline Obese & 19 & 19,00 & 1 & 1,00 & 2 & 2,00 & 24 & 24,00 \\
\hline Total & 94 & 94,00 & 4 & 4,00 & 2 & 2,00 & 100 & 100,00 \\
\hline
\end{tabular}

Source: HC Consultation

\section{Discussion}

As for blood glucose, Ibáñez et al studied a group of 185 aged between 5 and 18 years, with early pubarche in them measured the average serum insulin concentrations after a test of glucose tolerance was observed that concentrations average insulin were associated inversely with birth weight, which supports the points made ${ }^{[17]}$ in the same way, in these patients has been reported the existence of an increase in lipoprotein of low density lipoprotein of high density (LDL / HDL). This would indicate that these children develop a more atherogenic profile in early ${ }^{[18]}$.

Obesity is an emerging problem, especially among young people, and with a high potential for morbidity and mortality ${ }^{[19]}$ as it is associated with many diseases, not only in adults but also in children.

In 1993 in our country Cuba, a study on obesity where a prevalence of $9.3 \%$ was found and already in 1998 in a study carried out an increase to $13.1 \%$ was reported was made, this gives us the measure of the growing trend of obesity in recent years ${ }^{[20]}$, higher than this figures are reported in Chile where obesity pose values $15 \%$ with an annual increase of $1.5 \%$.

Currently according Burrows $\mathrm{R}$ one in four children is obese and one in three is overweight ${ }^{[21]}$.

Studies conducted in Mexico found that forty-five percent of children (47\% boys and $45 \%$ girls) categories were overweight $(21.1 \%)$, obesity $(23.5 \%)^{[22]}$.

Given the epidemic of overweight and obesity (SOB) suffering the adult population ${ }^{[23]}$, which in this age is associated with the leading causes of death, it is essential to know its magnitude, mechanisms and tools possible to reduce your damage, if this we add that diabetes mellitus is on the door of a pandemic is not difficult to argue that this occurs because the mechanisms of obesity to diabetes is known, so is the strict control of malnutrition by excess not reach debuting with diabetes and through these factors the process of atherosclerosis is accelerated, consistently decreasing life expectancy and quality of life, whether tangible and effective measures are not taken.

\section{Conclusions}

The high birth weight (macrosomia) does not constitute a predictor per se for the association of malnutrition by excess and diabetes. It is worrying the association excess malnutrition and diabetes in both groups.

\section{References}

1. Alpizar, M. Guide for comprehensive management of diabetic patients. (2001) Mexico El Manual Moderno.

2. Goldman., Bennett, J., Cecil, L., Manual Madrid Internal Medicine $21^{\text {st }}$ Ed. (2002) McGraw-Hill-Interamericana.

3. Sierra, I., Metabolism of Carbohydrates and its clinical significance. (1999) Bogota: Kimpres.

4. Tene, C.E., Espinoza-Mejia, M.Y., Silva-Rosales, N.A., et al. high birth as a risk factor for childhood obesity weight. (2003) Gac Med Mex 139(1): 15-20.

5. Wei, J.N., Li, H.Y., Sung, F.C., et al. Birth weight correlates differently With cardiovascular risk factors differently in youth. (2007) Obesity(silver apring) 15(6): 1609-1616.

6. Mehta, S.H., Kruger, M., Sokol, R.J. Being too large for gestational age precedes childhood obesity in African Americans. (2011) Am J Obstet Gynecol 204 (3): 265 e1-5.

7. TiconaRendón, M., Moon Ticona, L., HuancoApaza, D., et al. Nutritional status and metabolic abnormalities in children aged 8 to 10 years with a history of fetal macrosomia in Tacna, Peru. (2014) Rev peru ginecol Obstet 60(2): 117-122.

8. Guides ALAD of diagnosis, monitoring and treatment of diabetes mellitus type 2 extraordinary Edition 1. (2000) Latin American Diabetes

Association (ALAD).

9. Sanchez Medina, M., Diabetes in Colombia: a major public health problem (2000).

10. Mata, M., Antoñanzas, F., Tafalla, M., et al. The cost of type 2 diabetes in Spain. The CODE-2.España study. (2002) Gaceta Sanitaria 16 (6): 511-520.

11. Hogan, P., Dall, T., Nikolov, P. Economiccosts of diabetes in the U.S. in 2002. (2003) Diabetes Care 26(3): 917-932.

12. Mayer-Davis, E.J., Costacou, T. Obesity and sedentary lifestyles: Modifiable risk factors to prevent diabetes type 2. Diabetes. (2001) Curr Diab Rep 1(2): 170-176

13. Matthew, E.K., Diabetic risk taking: The role of information, education and medication. (1999) J Risk and Uncertainly 18(2): 147-164 
14. Brown, S.A., Garcia,A.A., Winchell, M. Reaching underserved populations and cultural competence in diabetes education. (2002) Curr Diab Rep 2(2): 166-176.

15. Chacra, Á. Education: How many efforts ... but how valuable! Current Diabetes Report.Latin America. (2002) 1(5): 342.

16. Gagliardino, J.J., Etchegoyen,G., A model educational program for people with Type 2 diabetes: Á cooperative Latin Ámerican implementatio cooperative study (PEDNID-la). (2001) Diabetes Care 24(6): 1001-1017.

17. Barker, D.J., Hales, C.N., Fall C.H., et al. Type 2 (non insulin dependent) diabetes mellitus, hypertension and hyperlipidaemia (SyndromeX): relation to reduced fetal growth. (1993) Diabetologia 36(1): 62-67.

18. Ibañez, L., Potau, N., De Zegher, F. Precocious pubarche, dyslipidemia, and low IGF binding protein-1 in girls: relation to reduced prenatal growth. (1999) Pediatr Res 46(3): 320-322.

19. Edo Martinez, A., Montaner Gomis, I., Bosch Moragaa, I., et al. Lifestyles, dietary habits and prevalence of overweight and obesity in children. (2010) Ate RevPediatr Primary 12(45).

20. Klotz, O., Manning, M.F. Fatty Streaks in the Intima of arteries. (1911) J Pathol 16: 211-220.

21. Burrows, R. Prevention and treatment of obesity since childhood: the strategy to reduce non-communicable chronic adult diseases. (2000) Rev Med Chile 128(1): 36-38.

22. Bacardí-Gascón, M., Jimenez-Cruz, A., Guzmán-González, J.V. High prevalence of obesity and abdominal obesity in school children between 6 and 12 years old. (2007) Bol Med Hosp Infant Mex 64(6): 362-369.

23. Flores-Huerta, S., Pérez-Cuevas, R., Garduño-Espinosa, J., et al. A look from health services to childhood nutrition mexicana.II.Problemas emerging: overweight and obesity. (2007) Bol Med Hosp Infant Mex 64(6): 399-407.

Ommega Online Publishers

Journal Title: Journal of Diabetes and Obesity (JDO)

Journal Short Name: J diabetes Obes
Journal ISSN: 2356-0494

E-mail: diabetes@ommegaonline.com

Website: www.ommegaonline.org 